\title{
Seismic Monitoring of a Slope to Investigate Topographic Amplification
}

\author{
Yunsheng Wang*, Jianxian He, Yonghong Luo, Shuihe Cao, Zihao He \\ State Key Lab of Geo-Hazard Prevention and Geo-Environment Protection, Chengdu University of \\ Technology, Chengdu, China
}

\begin{abstract}
Some earthquakes with a magnitude lower than Ms 7.0, such as Ludian earthquake in Yunnan in 2013, have triggered strong secondary geo-hazards in the form of slope failures. Topographic amplification is generally considered to be the main causal factor for these slope failures. However, until recently, this idea is not supported by appropriate seismic monitoring data. The Kangding Ms 6.3 earthquake on November 22 $2^{\text {nd }}, 2014$ was monitored in Lengzhuguan, Sichuan Province, located $56 \mathrm{~km}$ from the earthquake epicenter. Six monitoring instruments have recorded this earthquake. The horizontal and vertical component Peak Ground Acceleration (PGA), the site response directivity, the directional variation of the Arias intensity, and the acceleration response spectrum were determined from the data obtained. Conclusions could be drawn that the topographic amplification effect of the isolated ridge on the right bank was stronger than that of nearly linear slope on the left bank and the topographic amplification effect at a slope break was stronger than on a linear slope.
\end{abstract}

Keywords: Kangding Ms 6.3 earthquake, topographic amplification, slope seismic response, PGA, Lengzhuguan creek

\section{Introduction}

Based on geological studies and theoretical modeling, many authors have reported that topographic amplification effects occur at convex topography and slope breaks during earthquakes leading to more slope failures at those locations than at other parts of the slopes. The seismic response data analysis of the Central Chile earthquake in 1985 (Celebi 1987) revealed that the frequency range of the ground motion amplification could be obtained by the frequency ratio method and that an amplification effect was obvious at special topographical features and along a mountain ridge. Geli et al (1988) revealed that topographic amplification effects were obvious at hilltops where the slope width was approximately equal to the incident wavelength. The amplification effect was lower for incident Pwaves than for the incident S-waves; the topographic amplification effect of the primary wave and the vertical component of the secondary wave are slightly stronger than that of the horizontal component of the secondary wave, and the topographic amplification effect increased near adjacent ridges. Field surveys after Wenchuan Ms 8.0 earthquake on $12^{\text {th }}$ May, 2008 (Luo and Wang 2013) revealed that the horizontal components of the seismic waves were significantly enlarged when the slope width was close to the incident seismic wavelength: the amplification effect was distinct along narrow mountain ridges and spurs, at slope breaks, and on convex slopes. The Lushan Ms 7.0 earthquake on $20^{\text {th }}$ April, 2013 (Huang et al 2013) showed that the source of rock fall was usually near the top of steep slopes and near prominent changes in slope angle. Analysis of the seismic response of the Lengzhuguan slope during the Lushan earthquake revealed that the topographic

*Corresponding Author: Yunsheng Wang, wangys60@163.com, Tel: +86 13981969538 
amplification effect along the thin ridge of the right bank was significantly stronger than on the slopes of the left bank (Luo et al 2013). The highest peak ground acceleration (PGA) records during the Wenchuan earthquake were also caused by local topographic effects (Wen et al 2013). Qi et al (2003) simulated threecomponents of the acceleration distribution and carried out slope dynamic stability analysis on the right bank of Jinping hydropower station. Over 2000 secondary slope failures caused by the Lushan earthquake and large scale landslides triggered by the Ludian earthquake were assumed to be associated with topographic amplification effects, but real monitoring data of seismic response on various locations on slopes are still lacking.

With the support of the China Geological Survey Bureau and the National Science Foundation of China, we set up a monitoring section in Lengzhuguan in 2011. At 16:55 hours of November 22, 2014, a magnitude Ms 6.3 earthquake occurred in Kangding County, Sichuan, located $56 \mathrm{~km}$ in northwestern $\left(315^{\circ}\right)$ direction from the monitoring section. The six seismic instruments in the section (stations 1, 2, 3, 4 and 5) were triggered by the earthquake, and a series of data were obtained to study the topographic amplification factors.

\section{The Monitoring Profile}

The Lengzhuguan earthquake monitoring stations are located on both sides of Lengzhuguan river valley where it flows into Dadu River on the right bank (Figure 1). Two stations are located on the right bank and three stations on the left bank of Lengzhuguan river valley (Figure 2). One seismic monitoring instrument was set in each station from 1 to 4, and two monitoring instruments were set in station 5 (the outer one is $57 \mathrm{~m}$ from the portal and the inner one is $135 \mathrm{~m}$ from the portal). The ridge on the right bank reaches an elevation of $1520 \mathrm{~m}$, while the left bank is $1000 \mathrm{~m}$ high sloping terrain which is connected with the right concave bank of Dadu River. Station 1 is on the top of the ridge on the right bank and station 2 is half way up the ridge; station 3 is situated at a slope break, and station 4 and station 5 are located at different levels on the nearly linear slope. So we can study the different topographic amplification effects at the two banks of the canyon from station 1, 2 and 3, and the topographic amplification on the nearly linear slope at station 4 and 5. Earthquake motions were measured by the E-catcher strong motion seismographs (Application of Japan, Saitama city), with basic sensitivity parameters $1 \mathrm{~V} / \mathrm{G}$. A meter full scale is $2000 \mathrm{gal}\left(1 \mathrm{gal}=1 \mathrm{~cm} \cdot \mathrm{s}^{-2}\right)$, and the range of cycle frequency is $\mathrm{DC} \sim 20 \mathrm{~Hz}(-3 \mathrm{~dB})$.

\section{The Seismic Response Data}

The location parameters of the monitoring stations are shown in Table 1, the recorded waveforms are shown in Figure 3 and the ground motion parameter characteristics of each monitoring station are listed in Table 2.

The data reveal that the PGA of station 1 is 188.1 gal in EW direction on the right bank while the station 3 is 49.8 gal, so the PGA on the right bank is about three times as large as that on the left bank. The PGA of outer point (57 $\mathrm{m}$ from the portal) at station 5 is 1.15 times larger than the inner one (135 $\mathrm{m}$ from the portal).

The site response directivity can be effectively analyzed by examining the directional variation of the Arias Intensity (Ia) (Arias 1970). The Ia values in three directions for each monitoring station are shown in Table 2. The maximum horizontal Ia on the right bank is about 15 times as large as that on the left bank and the vertical Ia about 7.5 times. The horizontal and vertical Ia values of station 1 are 2.7 and 3.1 times, respectively, as much as those of station 2 , and for station 4 are 1.4 and 2.0 times larger than those of station 5 . The outer and inner Ia values at station 5 are at the same level. Therefore, the seismic energy at the right bank is larger than that at the left bank.

\section{The Acceleration Response Spectrum}

The concept of the acceleration response spectrum is based on Elastic System Dynamics (Biot 1941). A series of response spectrum curves were derived from a number of typical strong earthquake accelerations (Housner 1959). A 
a.

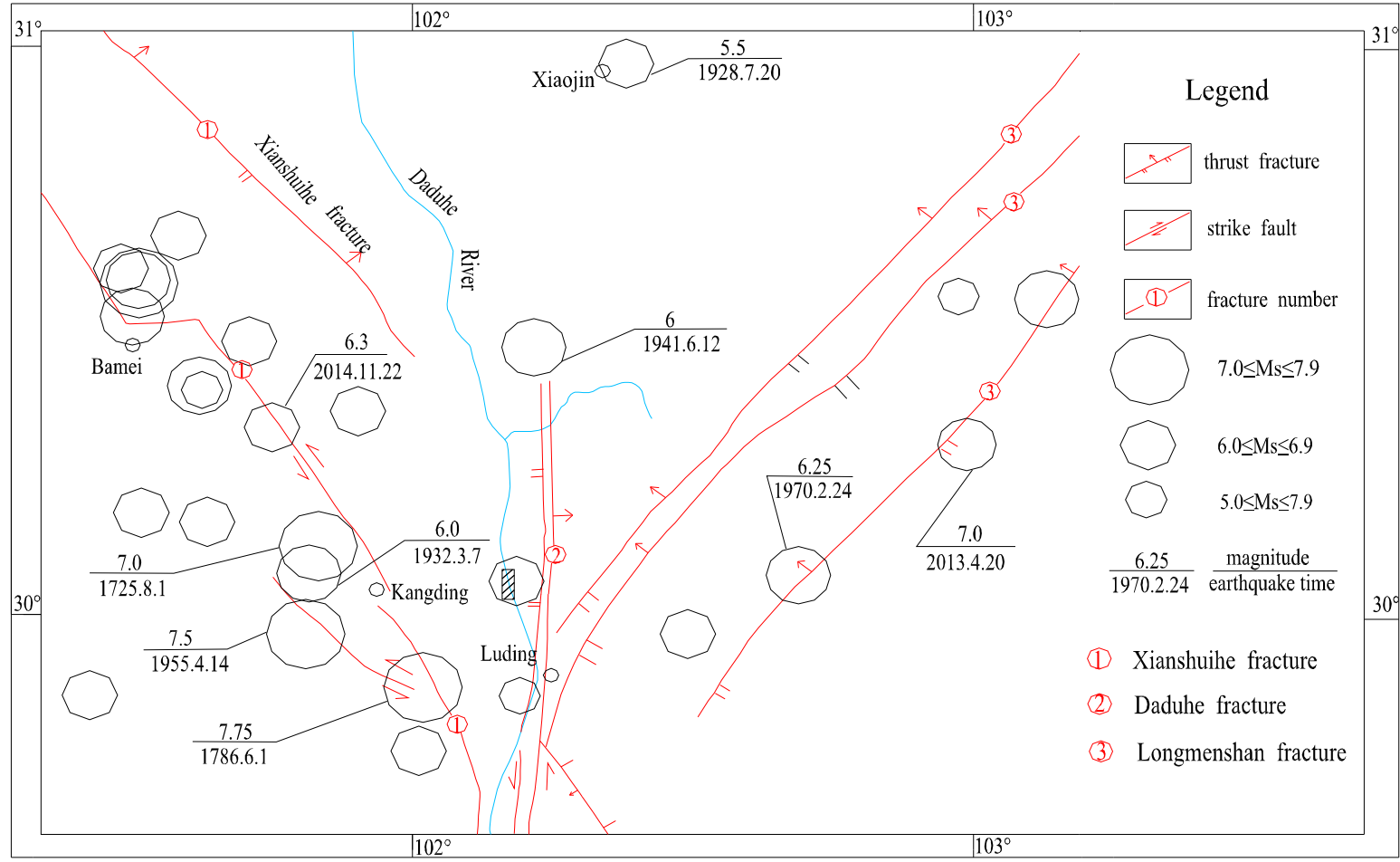

b.

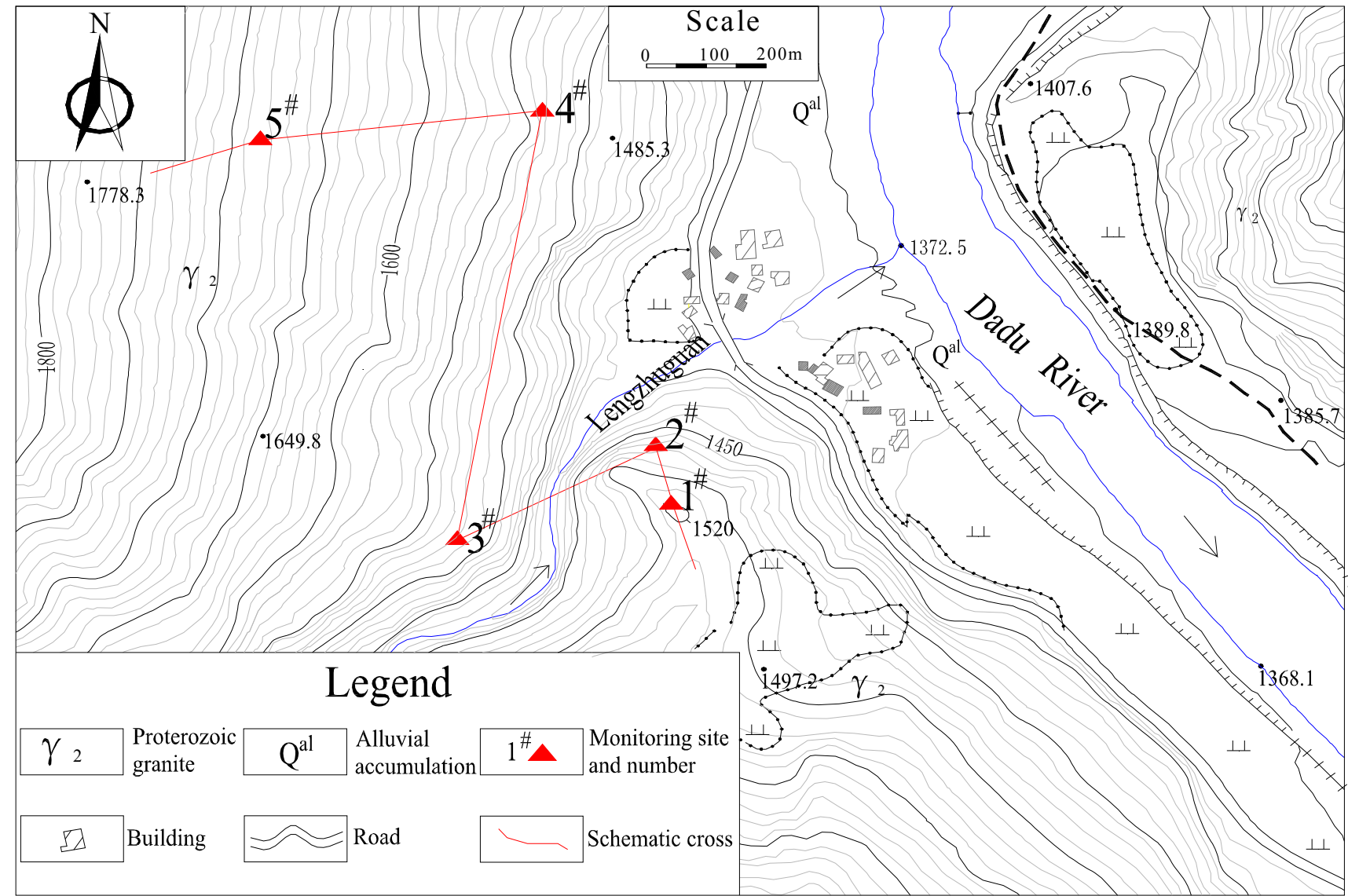

Figure 1 Location of the Lengzhuguan seismic monitoring section (a. the regional tectonic map; b. the monitoring station distribution plan) 


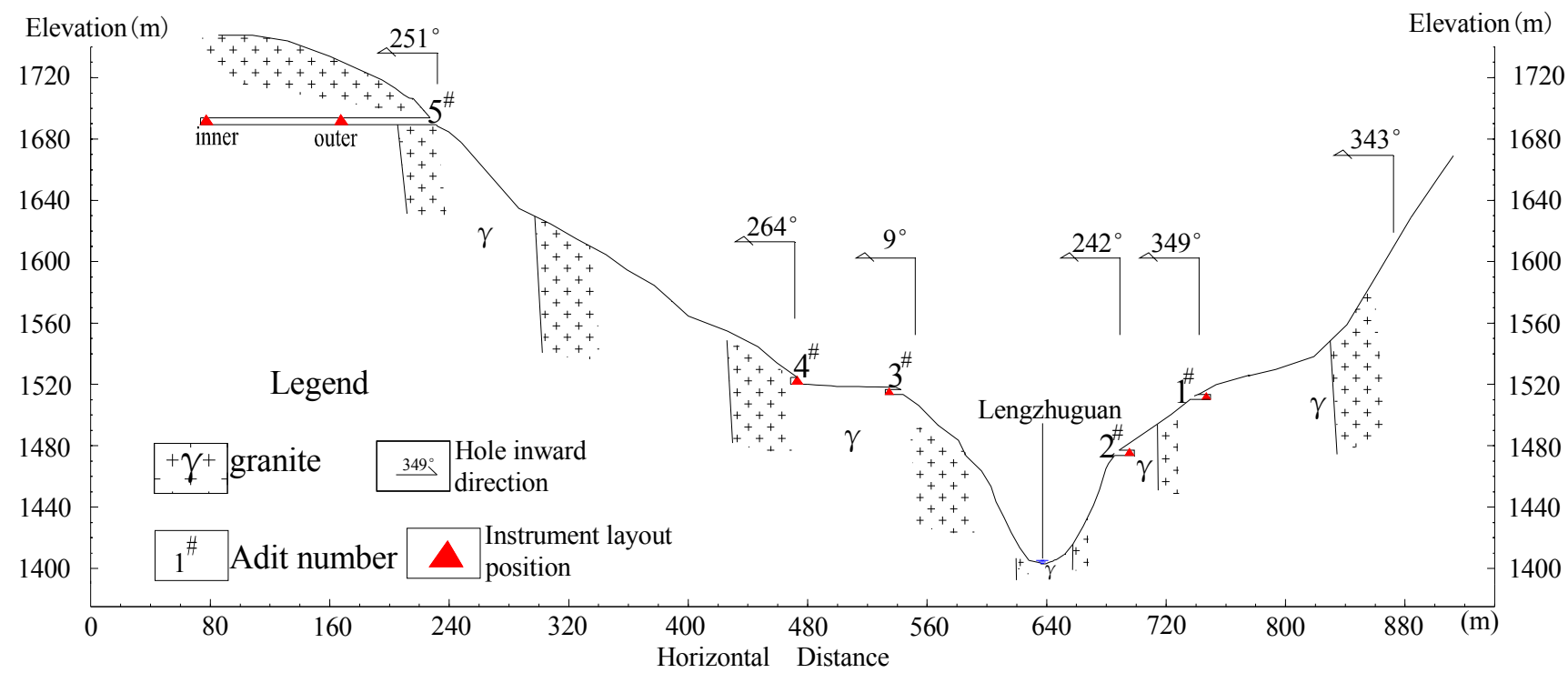

Figure 2 Lengzhuguan monitoring schematic section

Table 1 Location parameters of the monitoring stations

\begin{tabular}{cccccc}
\hline $\begin{array}{c}\text { Monitoring } \\
\text { station no. }\end{array}$ & $\begin{array}{c}\text { Elevation } \\
(\mathrm{m})\end{array}$ & $\begin{array}{c}\text { Epicentral } \\
\text { distance } \\
(\mathrm{km})\end{array}$ & $\begin{array}{c}\text { Distance to } \\
\text { Guza station } \\
(\mathrm{km})\end{array}$ & $\begin{array}{c}\text { Type of } \\
\text { bed rock }\end{array}$ & Degree of weathering \\
\hline 1 & 1516 & 56.2563 & 7.9045 & granite & moderate weathered \\
\hline 2 & 1478 & 56.2331 & 7.8201 & granite & moderate weathered \\
\hline 3 & 1518 & 56.0337 & 7.6618 & granite & moderate weathered \\
\hline 4 & 1520 & 55.9515 & 7.3536 & granite & moderate weathered \\
\hline 5 (Outer) & 1686 & 55.7189 & 7.1986 & granite & slightly weathered \\
\hline 5 (Inner) & 1686 & 55.7189 & 7.1986 & granite & slightly weathered \\
\hline
\end{tabular}

Table 2 The ground motion parameter characteristics in East-West (EW), North-South (SN) and Vertical Direction (VD)

\begin{tabular}{cccccccccc}
\hline \multirow{2}{*}{$\begin{array}{c}\text { Number of } \\
\text { monitoring stations }\end{array}$} & \multicolumn{3}{c}{ PGA (gal) } & \multicolumn{3}{c}{$\begin{array}{c}\text { Arias intensity } \\
\left(\mathrm{cm} \cdot \mathrm{s}^{-1}\right)\end{array}$} & \multicolumn{3}{c}{$\begin{array}{c}\text { Dominant frequency } \\
(\mathrm{Hz})\end{array}$} \\
\cline { 2 - 10 } & $\mathrm{EW}$ & $\mathrm{SN}$ & $\mathrm{VD}$ & $\mathrm{EW}$ & $\mathrm{SN}$ & $\mathrm{VD}$ & $\mathrm{EW}$ & $\mathrm{SN}$ & $\mathrm{VD}$ \\
\hline 1 & 188.1 & 147.6 & 111.8 & 24.7 & 25.5 & 6.0 & 2.04 & 2.54 & 5.07 \\
\hline 2 & 70.4 & 69.9 & 36.5 & 2.4 & 2.3 & 0.6 & 2.04 & 2.04 & 5.31 \\
\hline 3 & 49.9 & 62.4 & 36.6 & 1.7 & 1.6 & 0.8 & 4.42 & 3.31 & 9.29 \\
\hline 4 & 35.0 & 26.4 & 27.6 & 0.5 & 0.3 & 0.3 & 1.24 & 1.01 & 8.59 \\
\hline 5 (Outer) & 24.9 & 22.7 & 14.0 & 0.3 & 0.3 & 0.2 & 1.26 & 1.02 & 1.19 \\
\hline 5 (Inner) & 22.5 & 19.8 & 12.0 & 0.3 & 0.3 & 0.1 & 1.24 & 1.01 & 1.17 \\
\hline
\end{tabular}



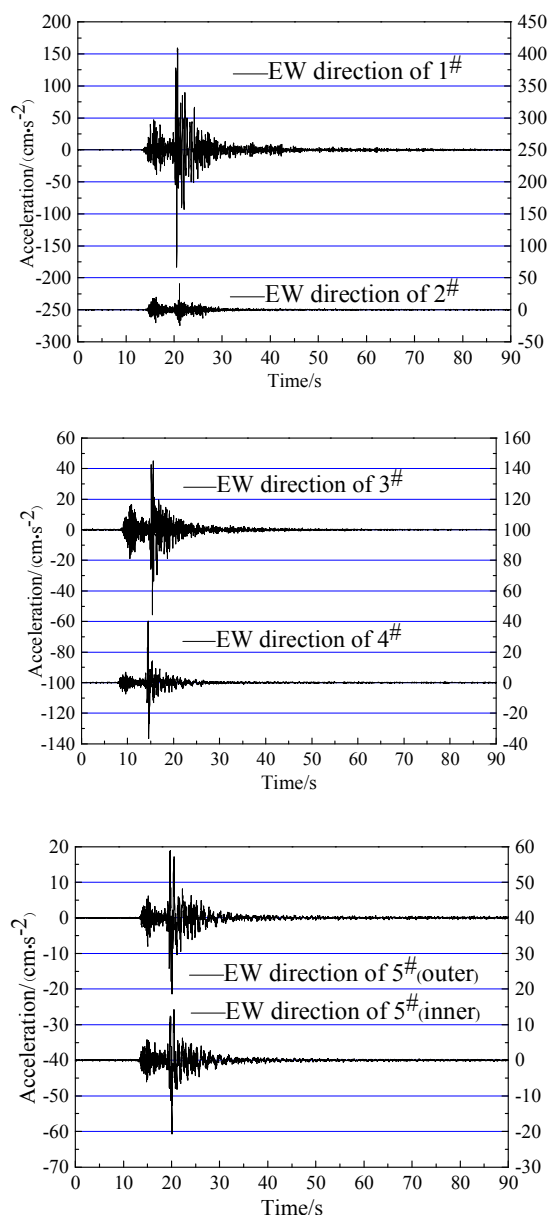
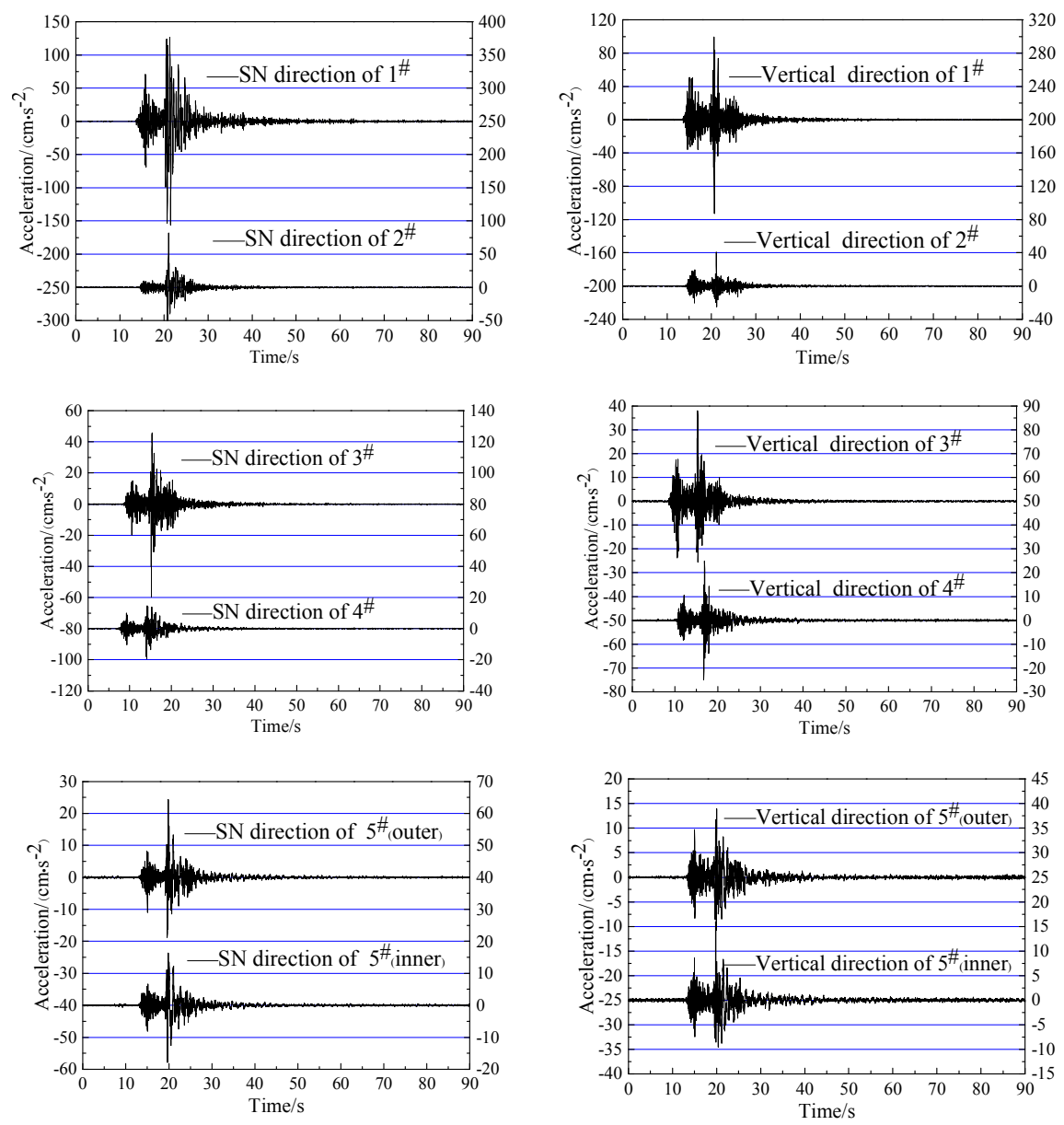

Figure 3 The waveforms in three directions of the monitoring stations 1, 2, 3, 4 and 5

response spectrum is simply a plot of the peak or steady-state response (displacement, velocity or acceleration) of a series of oscillators of varying natural frequency, that are forced into motion by the same base vibration or shock, and the essence is the reaction of the ground to the seismic motion characteristics. According to the specification of strong motion safety monitoring for hydraulic structures (DL/T 5416-2009), the horizontal and vertical acceleration response spectra with different damping ratios (for 0.05, 0.1 and 0.2) are calculated (Figure 4).

The acceleration amplitude decreases with the increase of the damping ratio, and is at the maximum with a damping ratio of 0.05 (Figure 4). The upward and downward trends of the horizontal and vertical acceleration response spectrum curves for each monitoring point are consistent, i.e., they reach the maximum and minimum values for the acceleration amplitude for different damping ratios at the same time. These results show that the seismic amplitude value is affected by the damping characteristics of the ground while the ground motion characteristics are not affected significantly. The horizontal acceleration amplitude at each monitoring point is larger than the vertical one at the different damping ratios, which is consistent with the waveform at the monitoring stations. The acceleration response spectrum curve of station 1 is about 3.1 times as large as the station 2 with the same damping ratio, and the vertical is 4.5 times large. The acceleration amplitude at station 1 with the damping ratio of 0.2 is also larger than at the station 2 with a damping ratio of 0.05 . It is also larger than those at each monitoring station at the left bank with a damping ratio of 0.05 . So the acceleration amplitude of the response spectrum on the right bank is bigger than that on the left bank. 
(a)

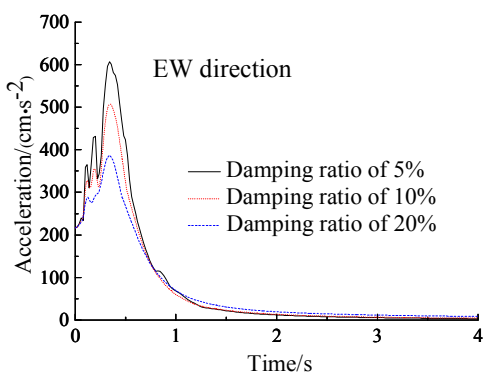

(b)

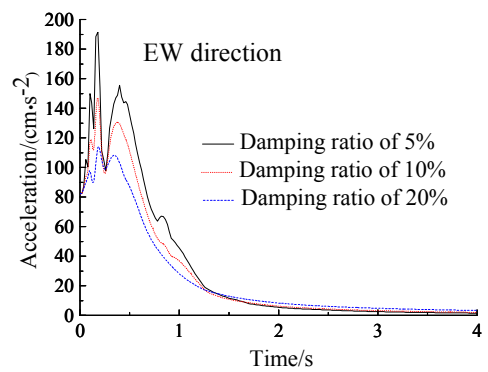

(c)

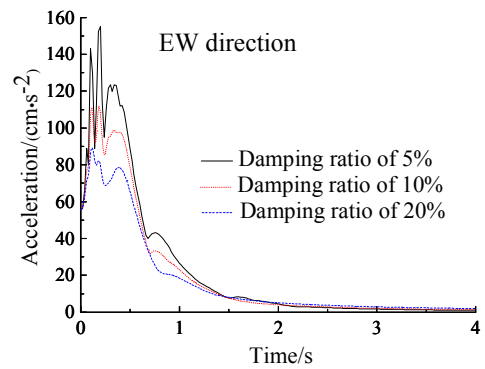

(d)

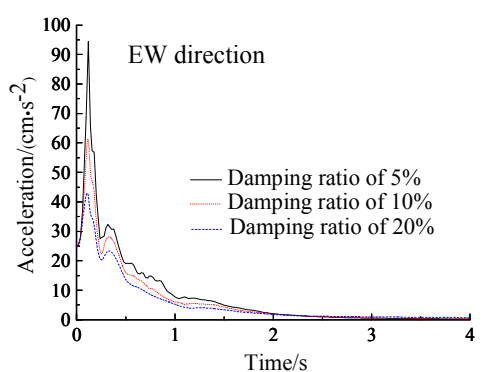

(e)

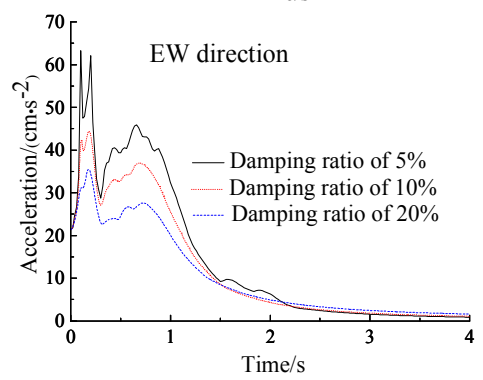

(f)

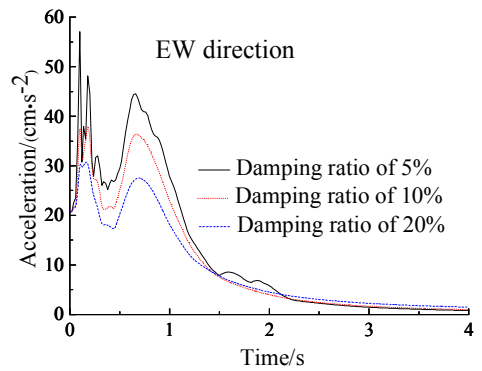

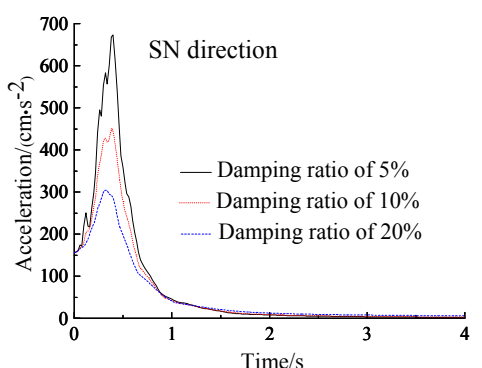
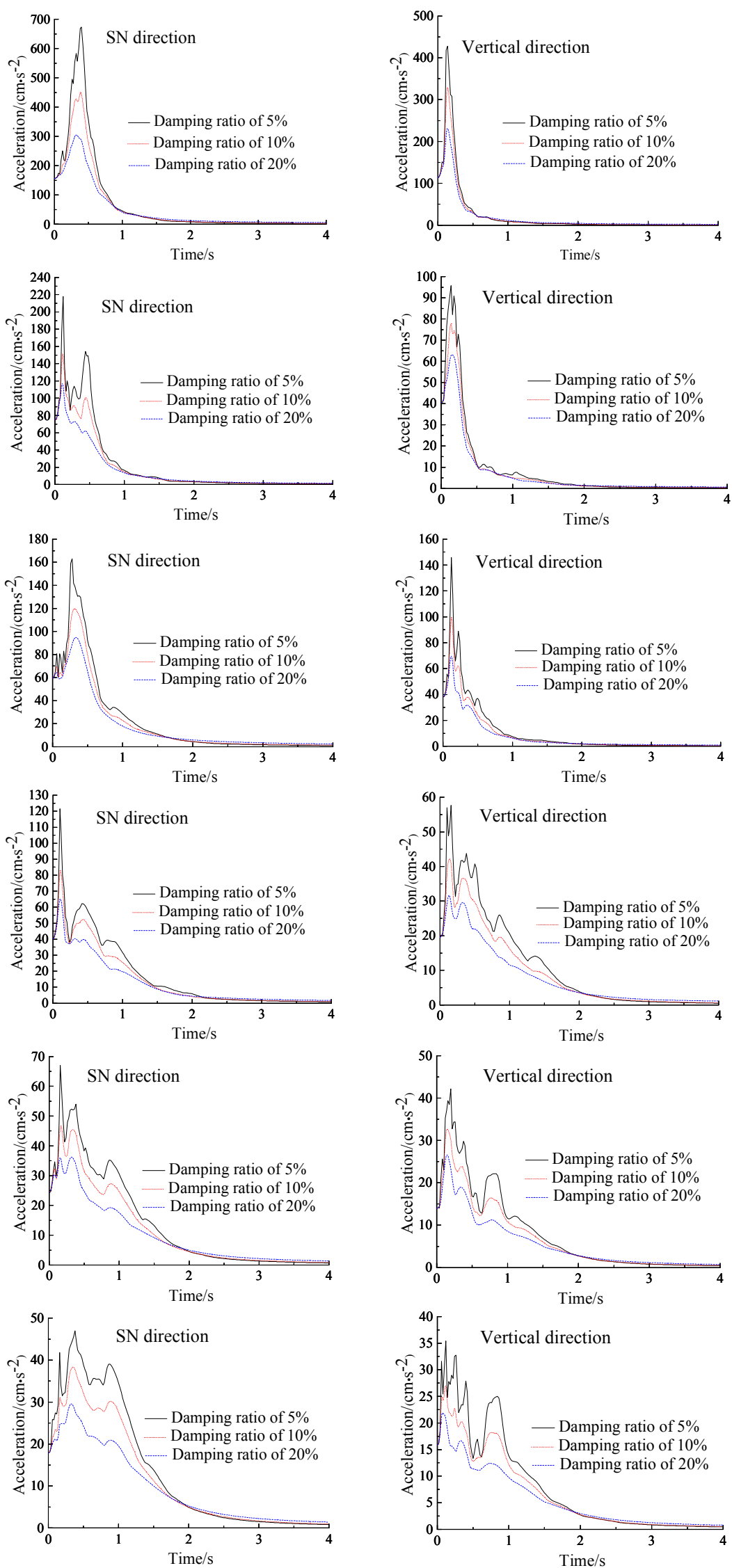

Figure 4 The acceleration response spectra at the monitoring stations: (a) station 1, (b) station 2, (c) station 3, (d) station 4, (e) station 5 outer and (f) station 5 inner 


\section{Topographic Amplification Effect}

At the Guza earthquake monitoring station (at a distance of $7 \mathrm{~km}$ from the Lengzhuguan monitoring section and with a position at the bottom of the valley) the horizontal and vertical components of PGA of the main shock records were 16.4 and 15.7 gal, respectively. We used these values as reference values for the Lengzhuguan section as the two stations, designed to record the reference values at the bottom of the valley in the Lengzhuguan section, unfortunately were not triggered by the Kangding earthquake. The PGA amplification coefficients for each monitoring station at Lengzhuguan are shown in Figure 5.

The ridge on the right bank of Lengzhuguan is shaped peninsular and the left bank is nearly linear (Figure 6). The amplification effect of the ridge on the right bank is stronger than that on the left nearly linear slope (Figure 5).

Station 3 is at a slope break while station 4 is at the middle of a linear slope, and both are at the same level. The magnification coefficients at station 3 in three directions are larger than these at station 4 (Figures 7 and 8), so we conclude that the topographic amplification effect at a slope break is stronger than on a linear slope. We can also conclude that the outer magnification coefficients at station 5 closer to the terrain surface are larger than that deep inside the rock mass. These conclusions are also consistent with the indoor model test reached by Wang and Wang (1987) and numerical results reached by Qi et al (2003) and Qi (2006).

The topographic amplification effect is scarcely affected by the lithology as the five stations are of the same lithology (granite), and their weathering degrees are similar.

\section{Conclusions}

Reference to Guza station of the main shock record of Kangding earthquake (its horizontal and vertical component PGA was 16.4 and 15.7 gal, respectively), the monitoring data on the two banks of Lengzhuguan section reveal obvious topography amplification effects: (1) the amplification effect is strongest on the peninsular ridge on the right bank and weaker on the left nearly linear slope; (2) the amplification effect at the slope break is stronger than that at the linear slope from the monitoring data of station 3 and station 4; (3) the amplification factor near the surface of the slope is larger than deeper into the rock mass from two motoring instruments at

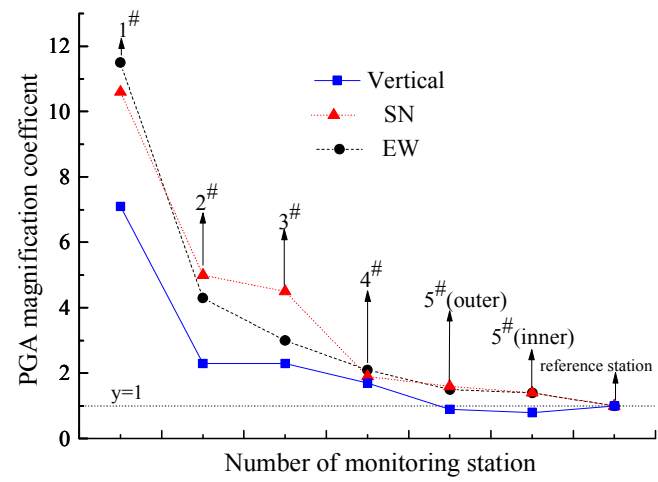

Figure 5 The PGA response coefficient of each monitoring station

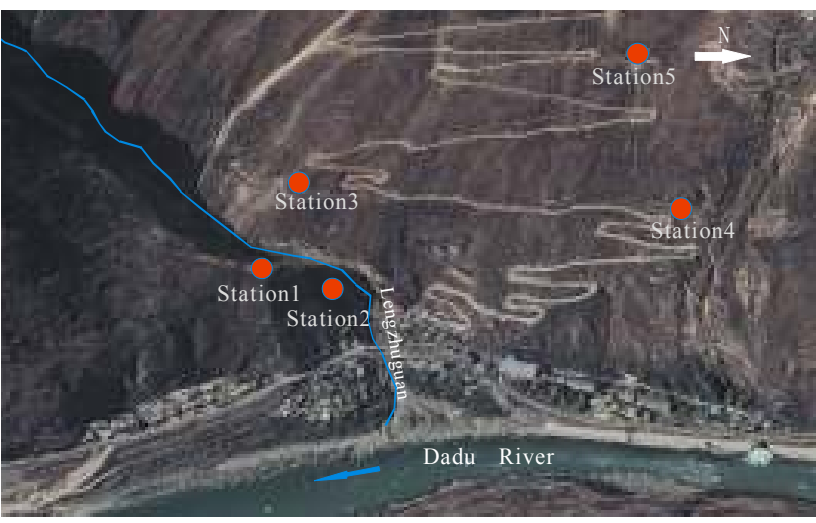

Figure 6 The peninsular ridge on the right bank of Lengzhuguan

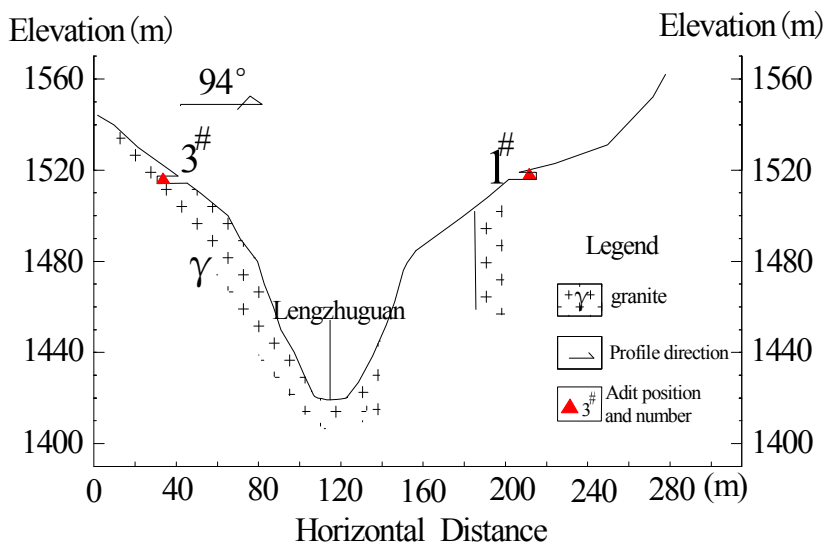

Figure 8 Station 3 at the slope break and station 1 on the ridge 


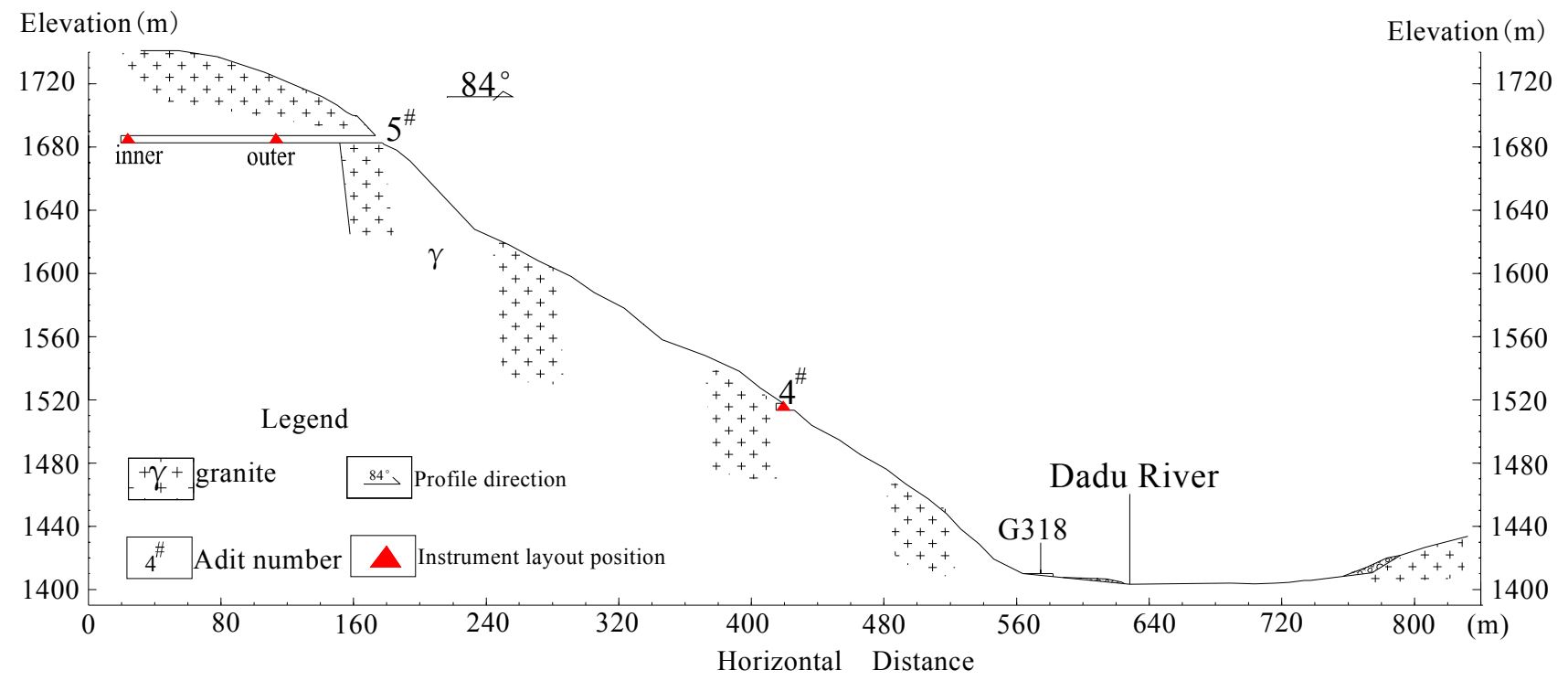

Figure 7 Nearly linear slope on the left bank of Lengzhuguan

station 5. It is clear that the characteristics of topography are important factors for slope stability, and that varying degrees of earthquake damage will be occur in different parts of slopes because of topographic amplification effects. What's more, we could study the mechanism of seismic landslide and slope failure with the monitoring data in different view.

\section{Acknowledgement}

This study is financially supported by the National Natural Science Foundation of China (41072231) and the Foundation of China Geological Survey (12120113009700). The authors would like to thank Niek Rengers for revising the article and his many helpful suggestions.

\section{References}

Arias, A., 1970. A measure of earthquake intensity in seismic design for nuclear power plants. MIT Press, Cambridge, Mass, pp. 438 483.

Biot, M.A., 1941. A mechanical analyzer for prediction of earthquake stress. Bulletin of the Seismological Society of America, 31(2): 151 - 171.

Celebi, M., 1987. Topographic and geological amplification determined from strong motion and aftershock records of March 1985 Chile earthquake. Bulletin of the Seismological Society of America, 77: 1147 - 1167.

Geli, L., P.Y. Bard and B. Jullien, 1988. The effect of topography on earthquake ground motion: a review and new results. Bulletin of the Seismological Society of America, 78: 42 63.

Housner, G.W., 1959. Behavior of structures during earthquakes. Journal of Engineering Mechanics Division, ASCE 85 (EM4): 109 129.

Huang, R.Q., Y.S. Wang, X.J. Pei, Y.S. Li, W.L. $\mathrm{Li}$ and Y.H. Luo, 2013. Characteristics of coseismic landslides triggered by the Lushan Ms 7.0 earthquake on the 20th of April, Sichuan Province, China. Journal of Southwest Jiao Tong University, 48(4): 581 - 589. (in Chinese). Doi: $\quad 10.3969 /$ j.issn.02582724.2013.04.001

Luo, Y.H. and Y.S. Wang, 2013. A study on the mountain slope ground motion topography amplification effect induced by Wenchuan Earthquake. Journal of Mountain Science, 31(2): 200 - 210. (in Chinese). Doi: 10.3969 /j.issn.1008-2786.2013.02.009.

Luo, Y.H., Y.S. Wang, Y. He, Y. Gao, Z. Liu and W.Z. Cao, 2013. Monitoring result analysis of Lengzhuguan slope ground shock response of 
Lushan earthquake of Sichuan, China. Journal of Chengdu University of Technology (Science \& Technology Edition), 40(3): 232 241. (in Chinese). Doi: 10.3969/j.issn.16719727.2013.03.02

National Energy Board of China. 2009. Specification of strong motion safety monitoring for hydraulic structures (DL/T 5416-2009). Beijing: China Electric Power Press.

Qi, S.W., F.Q. Wu and J.Z. Sun, 2003. General regularity of dynamic responses of slopes under dynamic input. Sci China Ser E, 46: 120 - 132. Doi: 10.1360/03ez0006.

Qi, S.W., 2006. Two patterns of dynamic responses of single-free-surface slopes and their threshold height. Chinese J. Geophys., 49(2): 518 - 523. (in Chinese).

Wen, R.Z., Y.F. Ren, W.H. Qi, T. Lu, Z.Y. Yang, Z.D. Shan and Y.L. Wang, 2013. Maximum acceleration recording from Lushan earthquake on April 20, 2013. Journal of Southwest Jiao Tong University, 48(5): 783 791. (in Chinese). Doi: $10.3969 / \mathrm{j}$.issn.02582724.2013.05.001

Wang, C.Y. and S.J. Wang, 1987. Study on stability of the bank slope of Ertan Reservoir under seismic condition, Problem of Rockmass Engineering Geomechanics, Vol. VII (in Chinese), Beijing: Science Press, 65 - 74. 